CHAPTER 7:

\title{
Investigating variations in computer and information literacy and computational thinking
}

\section{Chapter highlights}

There are differences in the proportion of variance between schools in computer and information literacy (CIL) and computational thinking (CT) scores.

- There were considerable differences in the variance for both CIL and CT as well as the proportion of variance found between schools across participating countries. (Table 7.1 and Table 7.6)

- Multilevel models explained most of the variance in CIL and CT scores at the school level while less variance was accounted for within schools. (Table 7.1 and Table 7.2)

There are consistent net effects on CIL and CT by personal and social background factors.

- Female gender tended to be positively related to CIL but negatively related to CT scores. (Table 7.2 and Table 7.7)

- Use of test language was a positive predictor of CIL and CT in some countries, in particular those with larger proportions of students speaking another language at home. (Table 7.2 and Table 7.7)

- Both expected university education and socioeconomic background are consistent positive predictors of both CIL and CT across countries, however, the effect sizes vary across countries. (Table 7.2 and Table 7.7)

There are consistent net effects on CIL and CT by a number of student-level predictor variables related to experience and use of information and communication technology (ICT) across countries.

- Students' daily use of ICT and experience with computers were consistent positive predictors of both CIL and CT. (Table 7.3 and Table 7.8)

- Availability of computers at home was a positive predictor in most countries but had weaker effects after controlling for personal and social background. (Table 7.3 and Table 7.8)

- Student reports on having learned about CIL-related tasks at school and on the use of general ICT applications in class tended to be a positive predictor of student CIL in a number of countries. (Table 7.3)

- Student reports on having been taught CT-related tasks had negative effects on CT scores across countries. (Table 7.8)

There are mostly inconsistent net effects on CIL and CT by school-level predictor variables related to ICT across countries.

- Schools' socioeconomic context (as measured by aggregated student scores reflecting family background) was a consistent positive predictor of CIL and CT in almost all countries. (Table 7.2 and Table 7.6)

- In the few countries where ICT-related school-level predictor variables had significant associations, these were often no longer significant after controlling for social context variables. (Table 7.5 and Table 7.10) 


\section{Background}

In previous chapters we have described some of the associations of computer and information literacy $(\mathrm{CIL})$ and computational thinking $(\mathrm{CT})$ with a number of variables, for example gender or those related to home background. This chapter investigates the combined influence of a number of variables on variations in CIL and CT including individual (student level) as well as context (school level) variables. This chapter addresses, for both CIL and CT, the following research questions:

RQ 2 What aspects of schools and education systems are related to student achievement?

RQ 3 What characteristics of students' levels of access to, familiarity with, and self-reported proficiency in using computers are related to student achievement?

RQ 4 What aspects of students' personal and social backgrounds (such as gender, socioeconomic background, and language background) are related to student achievement?

In this chapter, we use multilevel models to review the extent to which different factors at the student and school level are associated with variations in CIL and CT scores. Factors of interest will be those related to access to, use of, and familiarity with information and communications technology (ICT), school context factors, as well as variables reflecting the personal and social background of students.

Prior to the International Computer and Information Literacy Study (ICILS) 2013, research into learning outcomes related to ICT and factors influencing student knowledge in this area had generally been limited to national studies. In a number of countries these national evaluations provided evidence about factors explaining variation in ICT-related capabilities among students.

Sample surveys carried out as part of the Australian National Assessment Program for ICT literacy showed that students' gender (female), socioeconomic background, and experience and current use of computers were positive predictors of variation in ICT literacy (ACARA [Australian Curriculum, Assessment and Reporting Authority] 2012, 2015; MCEECDYA [Ministerial Council for Education, Early Childhood Development and Youth Affairs] 2010; MCEETYA [Ministerial Council on Education, Employment, Training and Youth Affairs] 2007). In the United States, results from the National Assessment of Educational Progress Technology and Engineering Literacy assessment indicated substantial differences with regard to the ICT skills scale between gender groups, parental education, ethnic background, and school location (US Department of Education, National Center for Education Statistics 2016).

ICT literacy was also assessed as part of the Chilean national assessment of students' ICT competencies, known as SIMCE TIC. Multilevel analyses of these data illustrated considerable variation among schools as well as effects of cultural background, socioeconomic status, and school characteristics (private/public, subsidies) on digital competencies (Román and Murrillo 2013). Further analyses also provided evidence of strong effects of prior achievement in reading and mathematics on digital competencies (San Martin et al. 2013).

Analyses of Norwegian grade 9 data collected in 2009 emphasized the importance of home factors (such as family background) but also of having a supportive school climate (Hatlevik 2009). In their analyses of survey data from Norwegian upper-secondary schools, Hatlevik and Christopherson (2013) revealed substantial variation within and between schools, with home conditions and academic aspirations as important predictors of digital competence. Multilevel analyses of data collected among grade 7 students also highlighted the importance of mastery orientation and self-efficacy as predictors of digital competence (Hatlevik et al. 2015).

At the international level, the Programme for International Student Assessment (PISA) assessed the performance of 15 -year-old students in digital reading across 16 countries (OECD [Organisation for Economic Cooperation and Development] 2011). Even though this international 
study assessed reading competencies in a digital environment, it also partly reflects skills related to CIL. Results from this study showed that socioeconomic background and computer use were positively associated with digital reading skills. However, no clear association was found with the use of computers at school.

Multilevel analyses carried out using data from ICILS 2013 showed that students' experience with computers as well as regular use at home had significant positive effects on CIL in many countries even after controlling for the influence of personal and social context. ICT resources, in particular the number of computers at home, did not have any effects once socioeconomic background was taken into account (Fraillon et al. 2014).

\section{Data and methods}

To develop a model to explain variation in each of $\mathrm{CI}$ and $\mathrm{CT}$ we used prior research literature and the contextual framework for ICILS 2018 in order to determine possible predictors of variation in CIL and CT for inclusion in the multivariate analyses presented in this chapter. The final indicators of home and school context in the model were chosen following exhaustive exploratory analyses of their conceptual importance as well as preliminary empirical evidence of their association with the two criterion variables CIL and CT.

Statistical modeling of the kind presented in this chapter assumes a logical structure where sets of predictor variables are used to explain variation in dependent variables. However, given the limitations of international studies such as ICILS and their cross-sectional design (Rutkowski and Delandshere 2016) it is not possible to draw firm conclusions about causal relationships from these data. Rather, these first analyses are conducted to review associations between contextual variables and $\mathrm{CI}$ or $\mathrm{CT}$, which may suggest possible causal relationships but are not necessarily robust evidence of causality.

The ICILS 2018 contextual framework (Fraillon et al. 2019) assumes that students' CIL and CT are influenced by context variables located at different levels (wider community, schools/ classrooms, individual learner, and home) which consist of antecedents as well as process-related factors. In the analysis of CIL and CT presented in this chapter, we included variables pertaining to the school/classroom context, the context of the individual learner, and the home context. Another distinction introduced for the analysis in this report is made between (1) personal and social background factors, and (2) context variables related to ICT and the learning context for CIL and CT.

The model chosen for analysis of both CIL and CT includes predictors which can be classified using the following broad categories:

- Personal and social background: Previous research and results from other analyses of this study (see Chapter 3) illustrated how much gender, students' expectations of educational attainment, and parental socioeconomic status are associated with students' CIL. These variables were included at the student level in Model 1 and Model 3 (see later for more detailed discussion of the models used).

- Social context of schools: The average socioeconomic status of the student body was used as a factor that has been shown to be associated with a variety of learning outcomes. This variable was included at the school level in Model 1 and Model 3.

- ICT resources and use at home: These predictors include ICT resources at home, personal experience with ICT, students' use of ICT at home and school, and students' experiences with learning about ICT at school. These variables were included at the student level in Model 2 and Model 3.

- ICT resources and use at school: Information on the schools' ICT resources and ICT use were collected through the ICT coordinator, principal, and teacher questionnaires. The school CIL learning context includes the expectations of school principals regarding teacher use of ICT 
for collaboration/communication at school and teacher reports of their average experience of the use of ICT for teaching at school. These variables were included at the school level in Model 2 and Model 3.

The personal and social student background characteristics included in the analysis were:

- Students' gender: This variable was coded as 1 for females and 0 for males.

- Students' use of the test language: This variable was coded as 1 for speaking the test language at home most of the time and 0 for other students.

- Students' expected university attainment: This variable reflects students' expectations to attain a university education (coded as 1 = expected, 0 = not expected).

- Students' socioeconomic background: This variable is composite index standardized to have a mean of $O$ and a standard deviation of 1 within each country and centered on school averages so that it indicates the effect of socioeconomic background within schools. The index consisted of factor scores from a principal component analysis of:

- Highest parental occupation (as indicated by the international socioeconomic index of occupational status scores of both parents);

- Highest parental education (categorical variable with $0=$ lower-secondary or lower education, 1 = upper-secondary education, 2 = post-secondary non-university education, 3 = university education); and

- Number of books at home (categorical variable with $0=0$-10 books, 1 = 11-25 books, 2 = 26-100 books, 3 = more than 100 books).

The schools' social intake was measured with the following variable:

- School socioeconomic context: This variable reflects the average of student scores on the composite index of socioeconomic background. It indicates the average socio economic background of enrolled students and the resulting social context in which students learn.

The following variables indicated ICT resources and use at home:

- Number of computers at home: Students reported the number of desktop and portable computers, the resulting indicator variable was coded 1 (two or more computers) and $\mathrm{O}$ (no or only one computer).

- Experience with computers: This variable reflects how long the individual student has used computers and was coded as 1 (five or more years of experience) and 0 (less than five years of experience).

- Use of ICT: This variable reflects the frequency with which each individual student uses ICT at school or outside of school for both school-related purposes or other purposes, and it was coded as 1 (daily use) and 0 (less than daily use).

- Students' reports on using general ICT applications in class: The three-item scale is based on a question that required students to indicate with what frequency they have used wordprocessing software, presentation software, and computer-based information sources at school. Values are item response theory (IRT) scores, which were standardized for this analysis within each country to having a mean of $\mathrm{O}$ and a standard deviation of 1.

- Students' reports on learning of CIL or CT: This consisted of

- Students' reports on learning of CIL-related tasks at school: The index is based on a set of eight items that required students to indicate whether they had learned about different $\mathrm{CIL}$ tasks ${ }^{26}$ at school. Values are IRT scores, which were standardized for this analysis within

26 The CIL-related tasks were: provide references to internet sources; search for information using ICT; present information for a given audience or purpose using ICT; work out whether to trust information from the internet; decide what information obtained from the internet is relevant to include in school work; organize information obtained from internet sources; decide where to look for information on the internet about an unfamiliar topic; and use ICT to collaborate with others. 
each country to having a mean of 0 and a standard deviation of 1 . This variable was only included in the model explaining variation of CIL.

- Students' reports on learning of CT-related tasks at school: The index is based on a set of nine items that required students to indicate whether they had learned about different CIL tasks ${ }^{27}$ during the current school year. Values are IRT scores, which were standardized for this analysis within each country to having a mean of $O$ and a standard deviation of 1. This variable was only included in the model explaining variation of CT.

The following school-level predictors reflect ICT resources and use at school:

- Availability of ICT resources for teaching and learning: This measure, based on the ICT coordinator questionnaire, was computed using reports on the availability of 13 different computer and ICT resources. ${ }^{28}$ The items were coded as available to teachers and students (2), available to either students or teachers (1), and not available (0), so that higher IRT scale scores indicate more ICT resources at school. Values are IRT scores, which were standardized for this analysis at the student level within each country to having a mean of 0 and a standard deviation of 1.

- School principals' reports on expectations for teacher communication using ICT: Principals reported whether teachers at the school were expected and required, expected but not required, or not expected to collaborate or communicate via ICT with teachers, parents, and students. The three items were used to derive an index where higher scale scores represent higher expectations/requirements in this respect. Values are IRT scores, which were standardized for this analysis at the student level within each country to having a mean of $O$ and a standard deviation of 1.

- Average time of teachers' experience with using ICT for teaching: This index reflects the average time teachers at the school reported to have used ICT for teaching purposes. Response categories for the item were scored as 0 (never), 1 (less than two years), 3 (two to five years), and 5 (more than five years).

- Teacher reports on ICT use for class activities: This IRT scale is based on a question asking teachers about the extent to which students used ICT for activities in class, and higher scores reflect greater use of ICT. Values are IRT scores, which were standardized for this analysis at the student level within each country to having a mean of 0 and a standard deviation of 1 .

During multivariate analyses, any issues relating to missing data tend to become more prevalent than in other forms of analysis because of the simultaneous inclusion of numerous variables. To address the missing data issue, we first excluded from the analyses the small proportion of students for whom there were no student questionnaire data (this was viable because only small proportions of students had missing data for the student-level variables). For the variables derived from the ICT coordinator questionnaire (ICT resources at school), school principal questionnaire (expectations for teacher collaboration/communication via ICT), and the teacher survey (teacher experience with ICT use during lessons, ICT use for class activities) there were higher proportions of missing data. These were treated by setting missing values to national averages or modes

27 The CT-related tasks were: to display information in different ways; to break a complex process into smaller parts; to understand diagrams that describe or show real-world problems; to plan tasks by setting out the steps needed to complete them; to use tools to make diagrams that help solve problems; to use simulations to help understand or solve real-world problems; to make flow diagrams to show the different parts of a process; to record and evaluate data to understand and solve a problem; and to use real-world data to review and revise solutions to problems.

28 The following ICT resources were used for scaling: digital learning resources that can only be used online; access to the internet through the school network; access to an education site or network maintained by education authorities; email accounts for school-related use; practice programs or [apps] where teachers decide which questions are asked of students (e.g., [Quizlet, Kahoot], [mathfessor]); single user digital learning games (e.g., [languages online]); multiuser digital learning games with graphics and inquiry tasks (e.g., [Quest Atlantis]); video and photo software for capture and editing (e.g., [Windows Movie Maker, iMovie, Adobe Photoshop]); concept mapping software (e.g.,

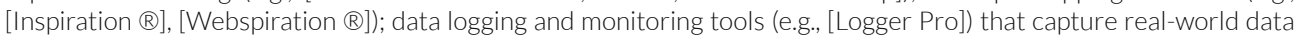
digitally for analysis (e.g., speed, temperature); a learning management system (e.g., [Edmodo], [Blackboard]); graphing or drawing software; e-portfolios (e.g., [VoiceThread]); digital contents linked with textbooks. 
respectively, and then by adding a missing indicator variable for missing school data (for each of the two indicators) and another one for entirely missing teacher data. This particular approach (see Cohen and Cohen 1975) was chosen given its simplicity and the relatively limited amount of missing values in a majority of countries.

On average across participating countries, data from about 92 percent of tested students were included in the analysis. In two countries (Germany and Uruguay) and one benchmarking participant (North Rhine-Westphalia, Germany) this proportion was below 85 percent and the results are annotated accordingly. For these countries, as well as those that did not meet the IEA sampling participation requirements, readers should interpret results with due caution. More detailed information on the multilevel modeling and treatment of missing data will be presented in the ICILS 2018 technical report (Fraillon et al. 2020).

In Luxembourg, student sample participation requirements were met and 38 of a total of 41 schools participated in the ICILS 2018 survey. Given this relatively low number of units available for analyses at the school level, which would have led to reduced statistical power and precision at the school level, data from this country are not included in the analyses presented in this chapter.

Due to the hierarchical nature of the survey data, we conducted multivariate multilevel regression analysis (see Raudenbush and Bryk 2002). We estimated, for each national sample, two-level hierarchical models with students nested within schools. The analyses were carried out using the software package Mplus (version 7; see Muthén and Muthén 1998-2012) and estimates were obtained after applying appropriate sampling weights at the student and school level. The school-level weights reflect the probabilities of schools to be selected as well as potential non-response adjustments, while student-level weights reflect the probabilities of individual students to be sampled within schools as well as possible adjustments for non-response. The weights were scaled so that the sum of weights is equal to the number of units at each level.

When interpreting results from a multilevel analysis, it is also important to be aware that student level variables in a two-level model have a different meaning from those in a single-level regression analysis. This is because student-level coefficients reflect the effect a variable has within schools. Because of this, effects at this level may differ from the findings that emerged from the bivariate analyses reported in previous chapters. ${ }^{29}$

In addition to estimates of overall and explained variance at the two levels in each of the countries, we will present unstandardized regression coefficients with indications of their statistical significance $(p<0.05)$. These predictor variables were coded in ways that allow a substantial interpretation of these coefficients. Positive coefficients indicate that the estimated net increase in CIL or CT score points equivalent with a corresponding increase of one in the predictor variable, while negative coefficients estimate a decrease. With regard to the interpretation of what a value of one means for each factor, we can distinguish three types of predictor variables:

- For dichotomous indicators, the regression coefficient reflects the estimated net effect in CIL or CT score points between the group with code of one when compared to all other students (female versus male students, speaking test language at home versus others, expecting a university qualification versus others, having two or more computers at home versus others, having at least five years of experience with computers versus others, daily ICT use versus others). ${ }^{30}$

29 Multilevel analysis allows the estimation of random effects models, where within-school effects vary across schools as well as interaction effects between school-level predictors and the slopes of student-level predictors within schools. However, in this first analysis of ICILS data regarding factors influencing CIL, all student-level effects were estimated as fixed effects that did not vary across schools.

30 For example, a coefficient of 5 for the gender indicator denotes that (within schools) females are predicted to have five score points more than males after controlling for all other variables, while a coefficient of - 5 would indicate that males are expected to have five score points more than females. 
- For categorical indicator variables (this only applies to the estimated years of teacher experience with ICT for teaching) the regression coefficient reflects the estimated effect of having one more year of experience across teachers in a school.

- For scale indicator variables regression coefficient indicates the change in CIL or CT score with an increase of one national standard deviation in the predictor variable (students' socioeconomic background, students' reports on learning about CIL-or CT-related tasks at school, students' reports on the use of general ICT applications in class, ICT coordinators', reports on ICT resources at school, principals' reports on expectations of teacher communication via ICT, teachers' reports on students' use of ICT for class activities).

When conducting the multilevel analysis of CIL and CT, four different models were estimated:

- Model $\mathrm{O}$ (the "null model") which included no predictor variables other than school intercepts;

- Model 1 which included only predictor variables related to the personal and socioeconomic background of students and schools' social intake;

- Model 2 which included only predictor variables related to ICT as student- and school-level predictors; and

- Model 3 which included all predictor variables from Models 1 and 2.

Using only the first group of predictors in Model 1, the second group in Model 2, and the combined set of predictors in Model 3, allows a review of the effects of background and ICTrelated predictors by themselves, as well as after controlling for the other types of predictors at student and school levels.

Because Model 0 provides estimates of the variance at each level (within and between schools) before the inclusion of predictors, it provides the point from which to determine how much the subsequent models explained the variance. Model 1 includes only those predictors that are either personal or social background factors, while Model 2 includes only those factors that are directly related to ICT (resources, familiarity, learning context). The final Model 3 provides information about how much variance is explained when both types of predictor variables are included in the model. Comparing effects of ICT-related Model 2 predictors with those from Model 3 illustrates the extent to which these effects are related to the effect of personal and social background predictor variables (either at the student or school level).

\section{Explaining variation in CIL}

Before considering the estimated effects at the student and school level, we compared the variance estimates for CIL at each level (students and schools) and overall, as well as the percentages of variance between schools (Table 7.1). For Chile, for example, we found that a variance in CIL scores of 6750, of which 4790 was observed within school (i.e., at the student level) and 1959 between schools (i.e., at the school level). This indicates that 29 percent of the variance is due to differences between schools. The following columns indicate the percentages of the variance that was explained by each model within and between schools. For example, in Chile Model 3 explains 16 percent of the variance within schools and 80 percent of the variance between schools.

Generally, we found considerable differences across participating countries. The overall variance (i.e., the combined variance at school and student level) ranged from about 4000 in Denmark to over 10,000 in Kazakhstan. The percentages of variance that was found between schools also varied substantially. While in Finland, Korea, and Moscow (Russian Federation) only around a tenth of the variance was found between schools, the corresponding estimates for Germany and Kazakhstan were around 50 percent and in Uruguay above 40 percent. 


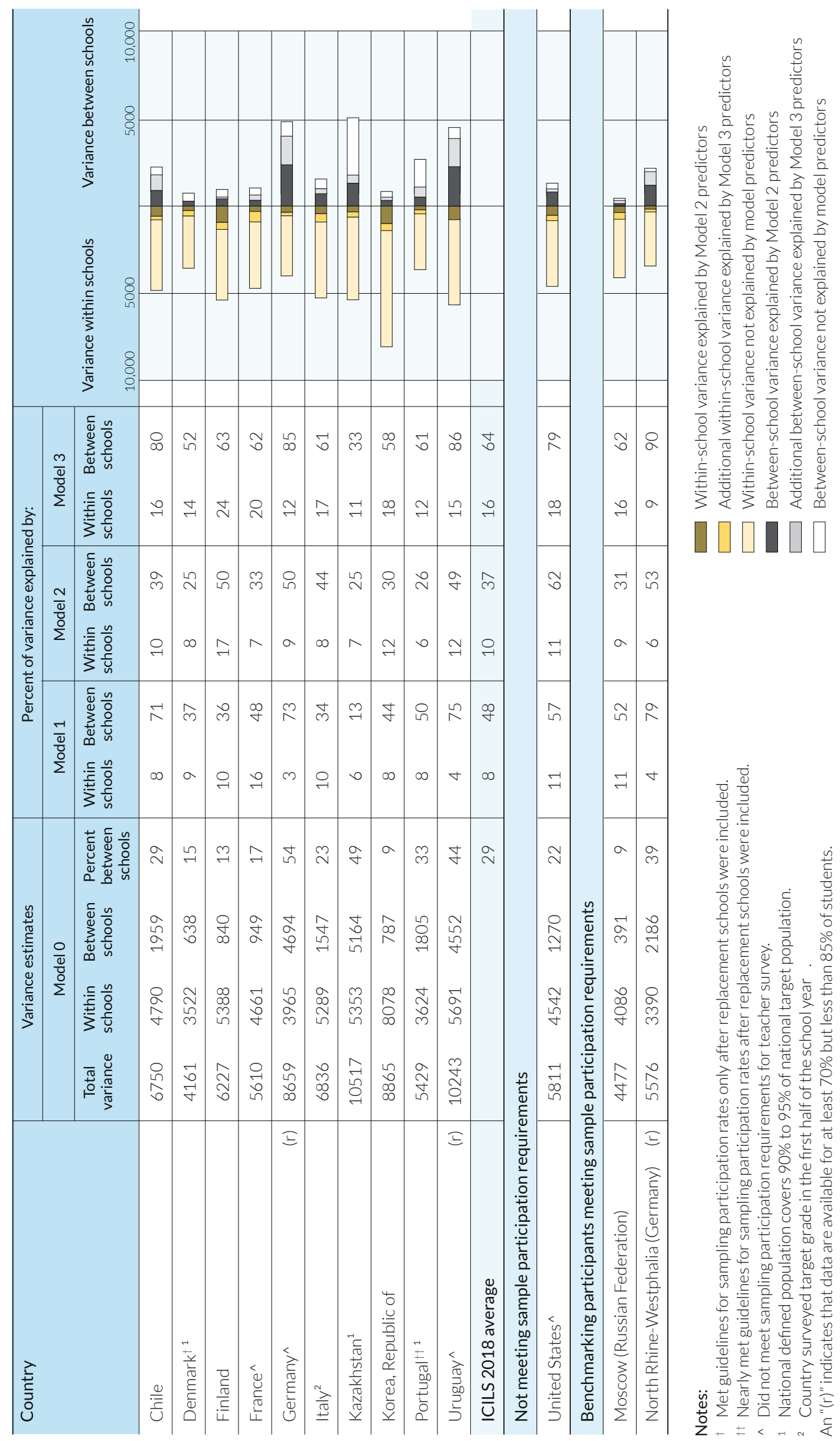


Model 1 (including the personal and social context factors) explained, on average, eight percent at the student level (ranging from 3\% in Germany to 16\% in France) and 48 percent at the school level (ranging from 13\% in Kazakhstan to 79\% in North Rhine-Westphalia, Germany). Model 2 (including ICT-related factors) explained on average 10 percent at the student level (ranging from $6 \%$ in Portugal and North Rhine-Westphalia, Germany, to 17\% in Finland) and 37 percent at the school level (ranging from 25\% in Denmark and Kazakhstan to 50\% in Finland and Germany). The final Model 3 (including all predictors) had an average variance explanation of 16 percent at the student level (lowest with 11\% in Kazakhstan and highest with 24\% in Finland) and 64 percent at the school level (lowest with 33\% in Kazakhstan and highest with $86 \%$ in Uruguay).

Note that this type of table (Table 7.1) aims to illustrate the amount of variance found at each level. In most countries substantial proportions of additional variance are explained once the latter type of variables is included in the final model.

When reviewing the unstandardized regression coefficients in the following tables, it is important to keep in mind that these are effects within schools that are possibly different from overall (single-level) effects of each of these factors. Furthermore, it is important to acknowledge that these are net effects (i.e., associations after controlling for all other variables in a particular model). Therefore, it is plausible to find effects that are somewhat different from bivariate associations reported in previous chapters.

Amongst the personal and social context factors (Table 7.2) included in Model 1 explaining variation in CIL, (female) gender tended to have positive effects in most countries (with the exception of Chile, Kazakhstan, Portugal, and Uruguay as well as the two benchmarking participants) and was on average associated with a net difference of $11 \mathrm{CIL}$ score points. The effects of using the test language at home were statistically significant in five countries (as well as in the two benchmarking participants) and on average there was a net effect of about 21 CIL score points. It should be kept in mind that in some countries there were relatively small subgroups of students speaking another language at home, which is reflected in the relatively large standard errors for the estimates in these countries. For both gender and test language, Model 3 coefficients (after controlling for effects of ICT-related variables) were very similar to those in Model 1.

In all participating countries (with the exception of Germany), expected university education was strongly associated with CIL, on average the effect was 27 score points in Model 1 and 23 in Model 3 , with considerable differences across countries. Larger differences across countries were observed for the effect of socioeconomic background, both at the student level (on average 11 points in Model 1, ranging from less than seven points in Korea and Portugal to almost 17 points in France) and at the school level (about 37 points in Model 1, ranging from about 16 points in Korea to 77 points in Germany).

Amongst the ICT-related variables at student level (Table 7.3), daily ICT use by students was consistently and strongly related to CIL. On average, it was associated with about 27 score points in Model 2 and 24 points in Model 3 (ranging from 15 in Italy and Kazakhstan to 38 in Germany). Also having five or more years of experience with computers was a statistically significant predictor in all countries, with an average effect of almost nine score points in Model 2 and eight points in Model 3 (with significant coefficients ranging from about three in France to 13 in Korea). Having two or more computers at home was a positive Model 2 predictor in six out of 10 countries (on average associated with almost $11 \mathrm{CIL}$ score points, and significant effects ranging from seven in Portugal to about 16 in Denmark, France, and the benchmarking participant Moscow, Russian Federation). In Model 3, the effect of this variable was statistically significant in only five countries and the average effect was less than six score points after controlling for personal and social context variables. 


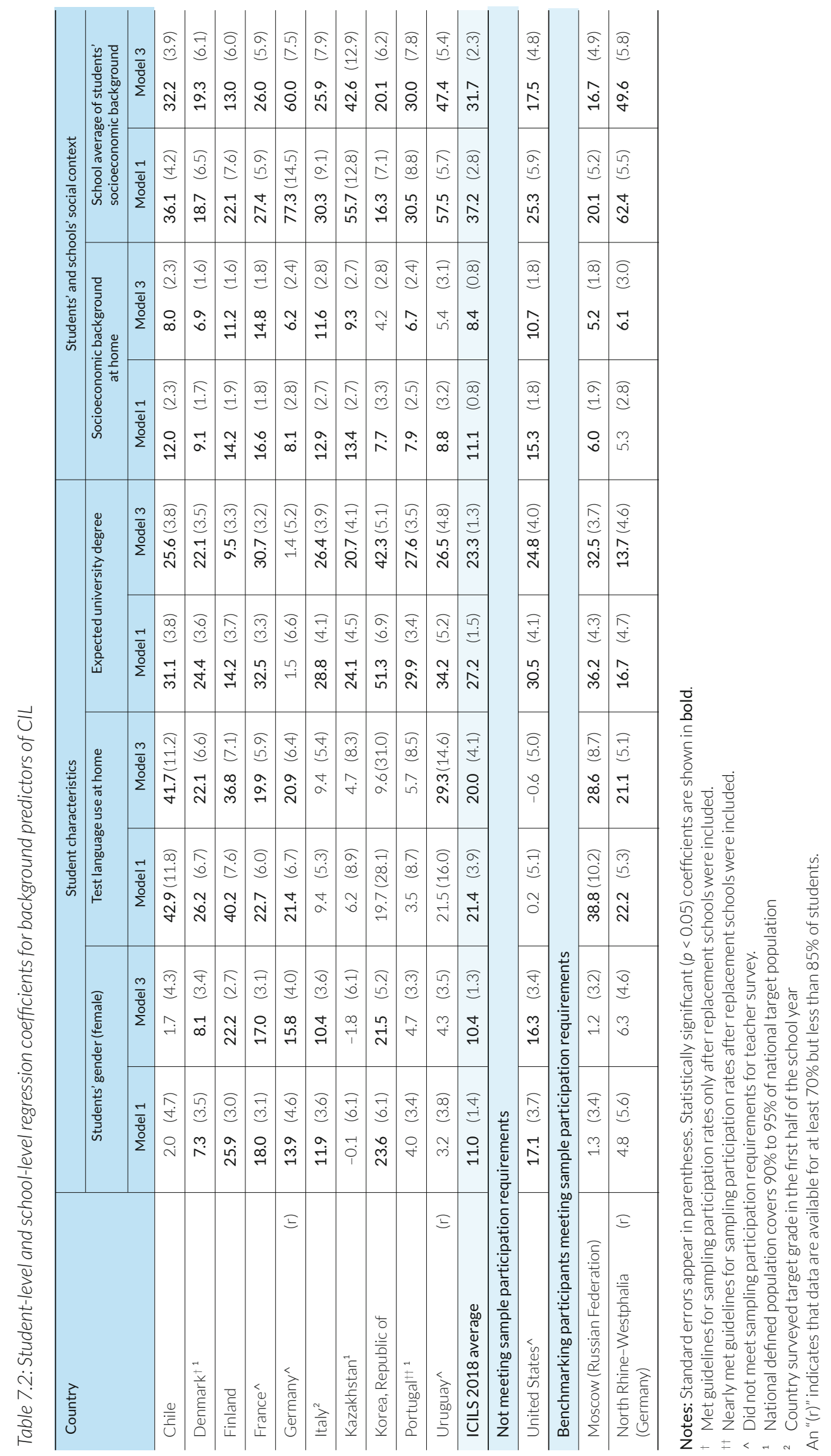




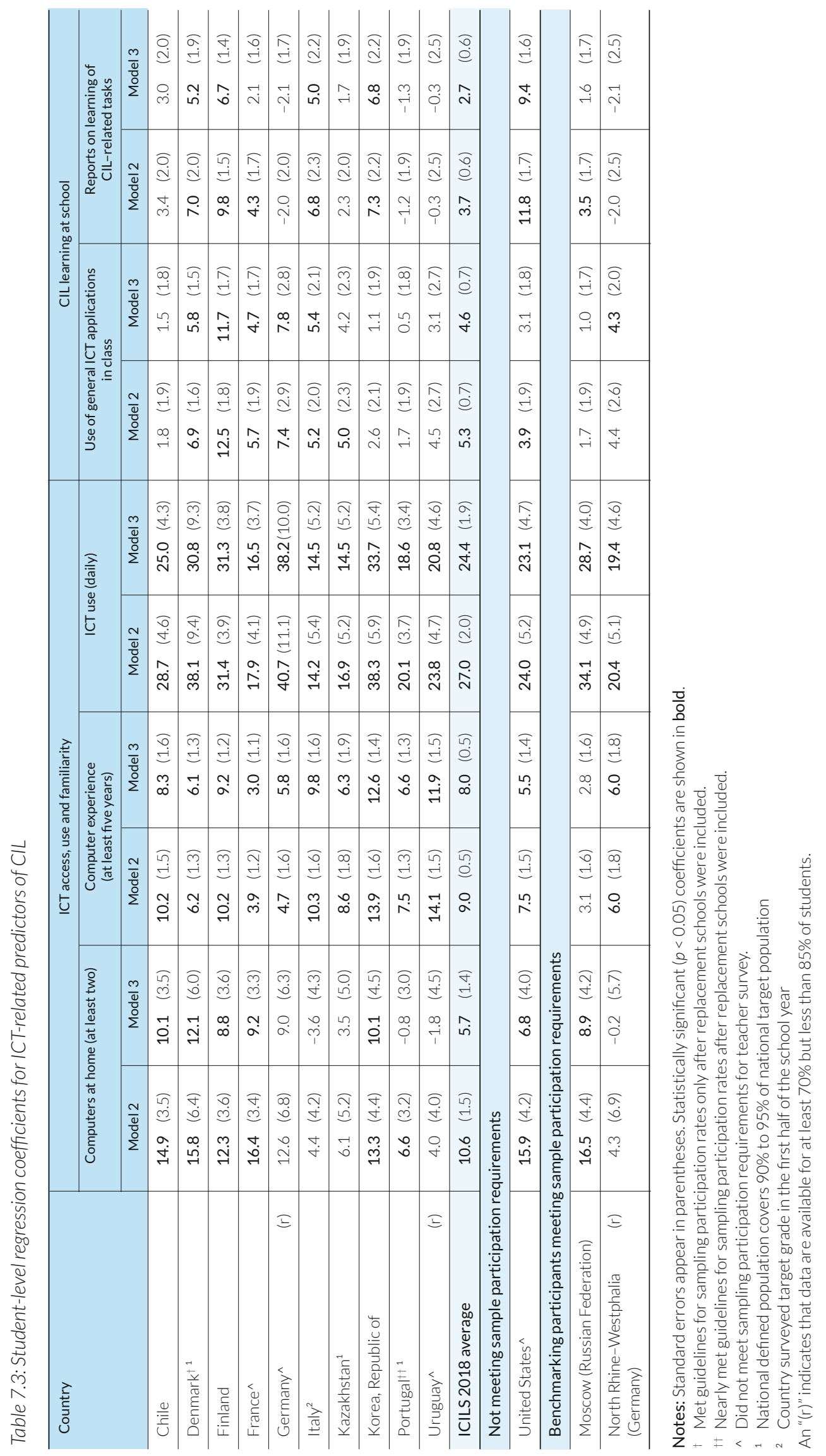


Students' reports on the use of general ICT applications during class had positive associations with CIL in five out of 10 countries, and on average one national standard deviation was associated with over five points in Model 2 and less than five points in Model 3. Students' perceptions of having learned about CIL-related tasks was a significant predictor in five countries and the benchmarking participant Moscow (Russian Federation) in Model 2 (with an average effect of almost four points), and in four countries in Model 3 (on average associated with less than three points).

When reviewing the effects of school-level predictors, we observe less consistency in the associations of these variables with CIL (Table 7.4). School expectations of teacher collaboration or communication via ICT was a significant positive Model 2 predictor in Germany (with 23 points) and Portugal (with 12 points), as well as in the benchmarking participant North RhineWestphalia (Germany). In Model 3 this factor was only significant in Germany (with a regression coefficient of 10 points).

ICT coordinator reports on the availability of school resources had significant positive effects on CIL in Germany (24 points) for Model 2. This variable was a positive predictor in Germany and Portugal for Model 3 after controlling for social context variables.

The average years of experience of teachers using ICT for teaching was a significant positive Model 2 predictor of CIL in Chile, Kazakhstan, Uruguay, and the benchmarking participant of North Rhine-Westphalia (Germany). However, after controlling for personal and social background variables in Model 3 this was only a significant positive predictor in Chile and North RhineWestphalia (Germany). Teacher reports on students' ICT use for class activities had significant positive associations with CIL for Model 2 in Finland and France. However, no significant effects in any of the countries meeting IEA sample participation requirements were recorded after controlling for social context variables as part of Model 3.

We summarized the results by displaying the numbers of significant positive and negative effects per country (by accounting only for countries meeting IEA sample participation requirements) in each of the models (Table 7.5). For example, for (female) gender, we recorded six instances where this Model 1 predictor had statistically significant positive effects across countries, while there were no countries where this variable had a negative effect. The same numbers were found when including all predictors in Model 3. Generally, we can observe that while student-level ICT-related variables remain significant after controlling for personal and social context variables (i.e., comparing Model 2 and 3), the few significant associations of school-level variables in Model 2 are further reduced after controlling for social context factors in Model 3.

\section{Explaining variation in $\mathrm{CT}$}

To explain variation in students' CT scores, we applied almost the same models as for CIL. The only difference was the use of the scale reflecting students' report on learning about CT-related tasks, instead of including the scale reflecting students' perceptions of having learned about CILrelated tasks at school. The analyses included data from six countries that met the IEA sampling participation requirements, data from the United States (which were reported separately as they had insufficient participation rates), and data from the benchmarking participant North RhineWestphalia (Germany) (data which are also included in the German national sample).

The results regarding the variance estimates for $\mathrm{CT}$ (overall, within, and between schools) and variance explanation by different models at each level are somewhat similar to those for CIL. (Table 7.6). There was considerable variation with regard to the overall variance of CT scores across countries, ranging from slightly below 7000 in Denmark and Portugal to more than 12,000 in Germany and Korea. The proportion of variance between schools also differed considerably, ranging from seven percent in Denmark to 46 percent in Germany. On average across countries, the proportion of variance between schools was 20 percent. Model 1 predictors (related to 


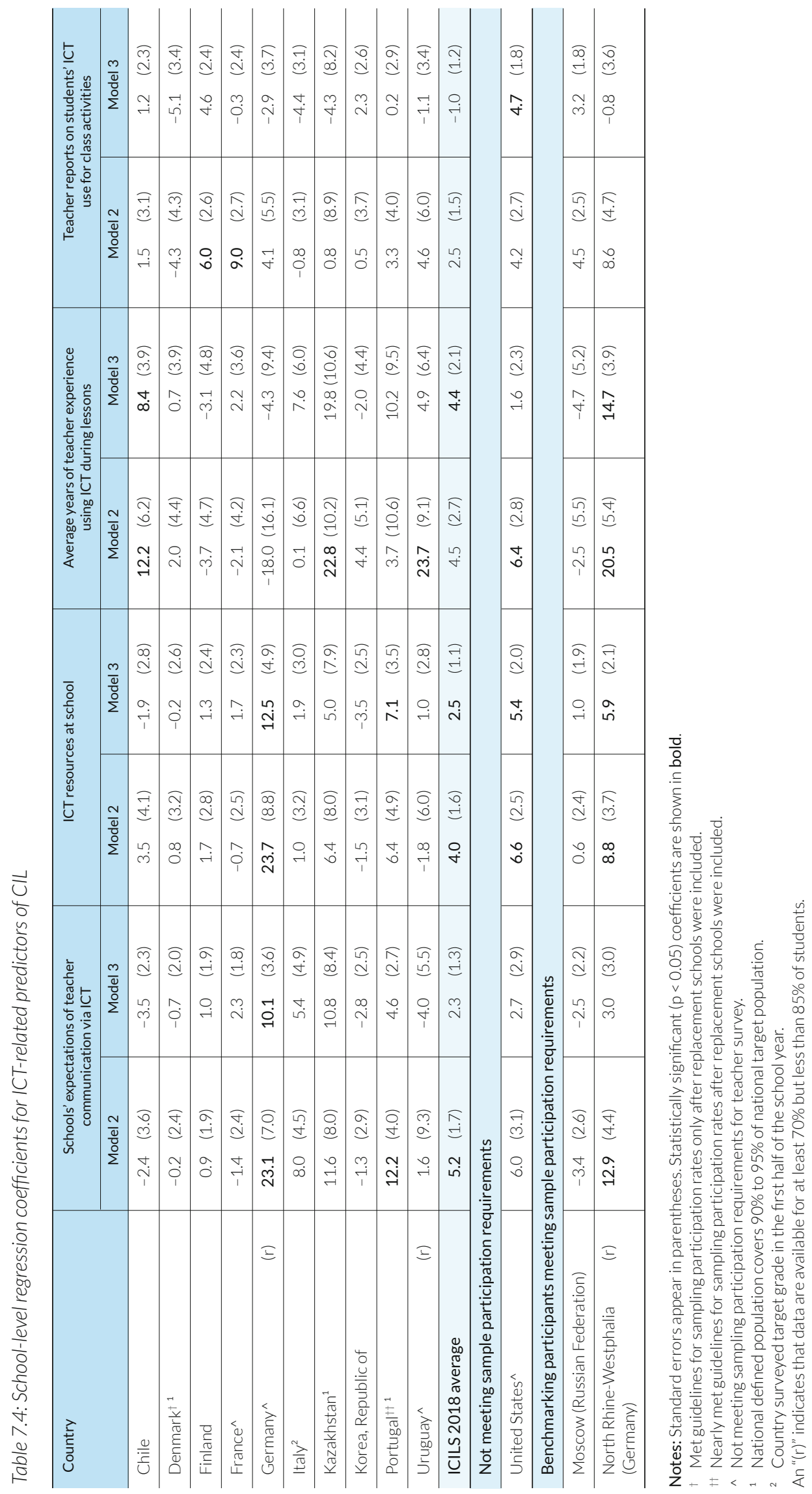




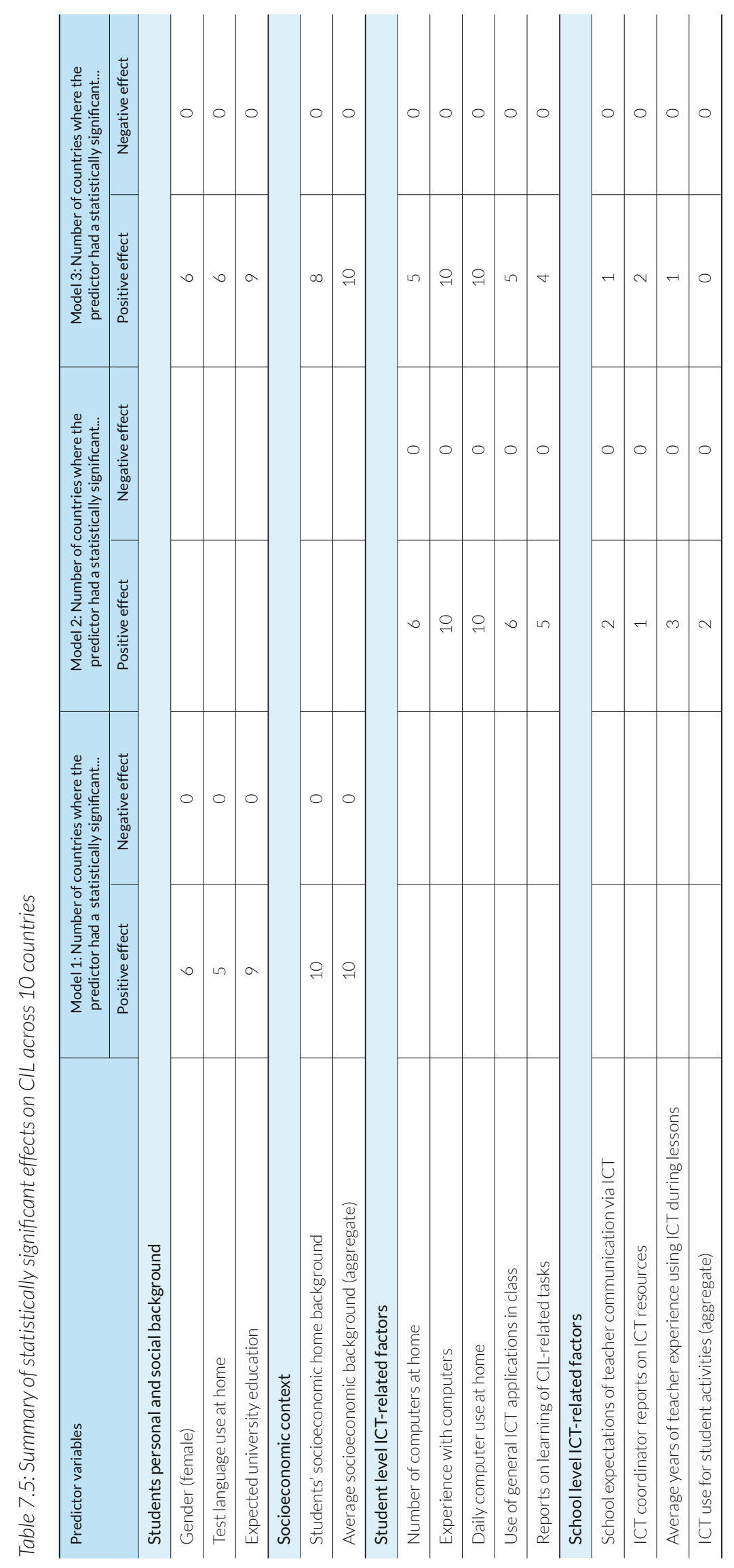




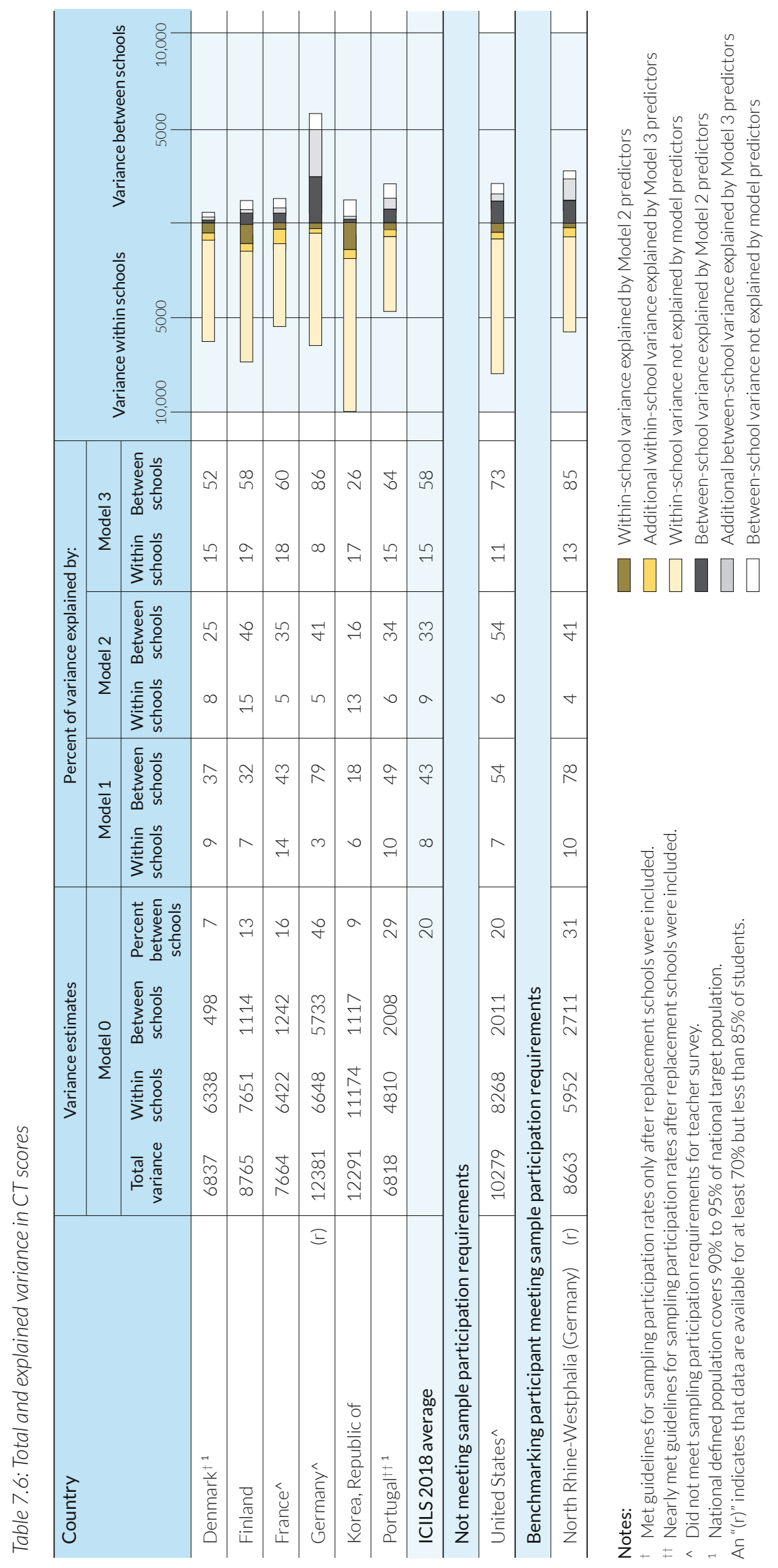


personal and social background) explained on average eight percent within schools (ranging from 3\% in Germany to 14\% in France) and 43 percent between schools (ranging from 18\% in Korea to $79 \%$ in Germany). The corresponding estimates of explained variance for Model 2 were nine percent within schools (ranging from 5\% or less in France, Germany, and the benchmarking participant North Rhine-Westphalia, Germany, to 15\% in Finland) and 33 percent between schools (ranging from 16\% in Korea to 46\% in Finland). For Model 3 these were 15 percent on average within schools (lowest was $8 \%$ in Germany and highest was 19\% in Finland) and 58 percent at the school level (lowest was 26\% in Korea and 86\% in Germany).

When reviewing the unstandardized regression coefficients for variables related to personal and social background (Table 7.7), we observed relatively strong and mostly significant negative associations with female gender in all countries except Finland, where a positive relationship was observed (Model 1). On average we recorded a net effect of about -12 score points. When comparing these results with the (mostly smaller) gender differences reported in Chapter 4 , readers should be mindful that the coefficients presented here are those estimated within schools and after controlling for other variables in the model. Typically, gender effects remained unchanged after taking other ICT-related factors into account (Model 3). However, in some countries the negative coefficients were somewhat stronger than in Model 1.

Use of test language at home had statistically significant positive effects on CT score in four countries (Chile, Finland, France, and Germany) and the benchmarking participant North Rhine-Westphalia (Germany) in both Model 1 and Model 3. Expected university education was consistently a significant positive predictor of $\mathrm{CT}$ (similar to the results for CIL), with the exception of Germany. On average we observed a net effect of almost 21 score points, which was only slightly lower for Model 3 where ICT-related factors were considered as well.

The within-school effects of socioeconomic background were significant and positive in all countries, on average across participating countries one national standard deviation was associated with a change of almost 15 score points in Model 1 and with over 12 points in Model 3. However, they ranged from less than 10 points in Germany to more than 20 score points in France. The effects at the school level were significant and positive in all countries except Denmark and Korea, in both models. For Model 1, we recorded effects of about 30 score points on average, with significant effects ranging from about 21 points in Finland to almost 88 points in Germany.

When reviewing the effects of ICT-related variables on CT at the student level (Table 7.8), we noted similar results to those found for CIL. The most consistent positive predictor was students' daily use of ICT, associated with more than 33 points on average, ranging from about 20 (in France) to almost 48 score points (in Korea). These coefficients were only slightly smaller for Model 3 after controlling for personal and social background factors, with an average effect of 31 points. Having five or more years of experience with computers was also a positive and significant predictor in all countries except Germany, with an average effect of almost nine score points in Model 2 (and about eight points for Model 3). Larger effects for this predictor of 10 or more score points were observed in Denmark, Finland, and Korea.

Having two or more computers at home had significant positive effects for Model 2 in all countries except Germany and Portugal. On average across participating countries, we observed an effect of about 12 score points. However, after controlling for factors related to personal and social background, for Model 3 this predictor was only significant in Finland with a considerably smaller effect coefficient. In Portugal, for Model 3 we recorded a significant negative effect after controlling for personal and social background factors.

Student report on the use of general ICT applications in class had significant positive associations within schools with CT in Denmark, Finland, and France. For Model 2 in these countries one 


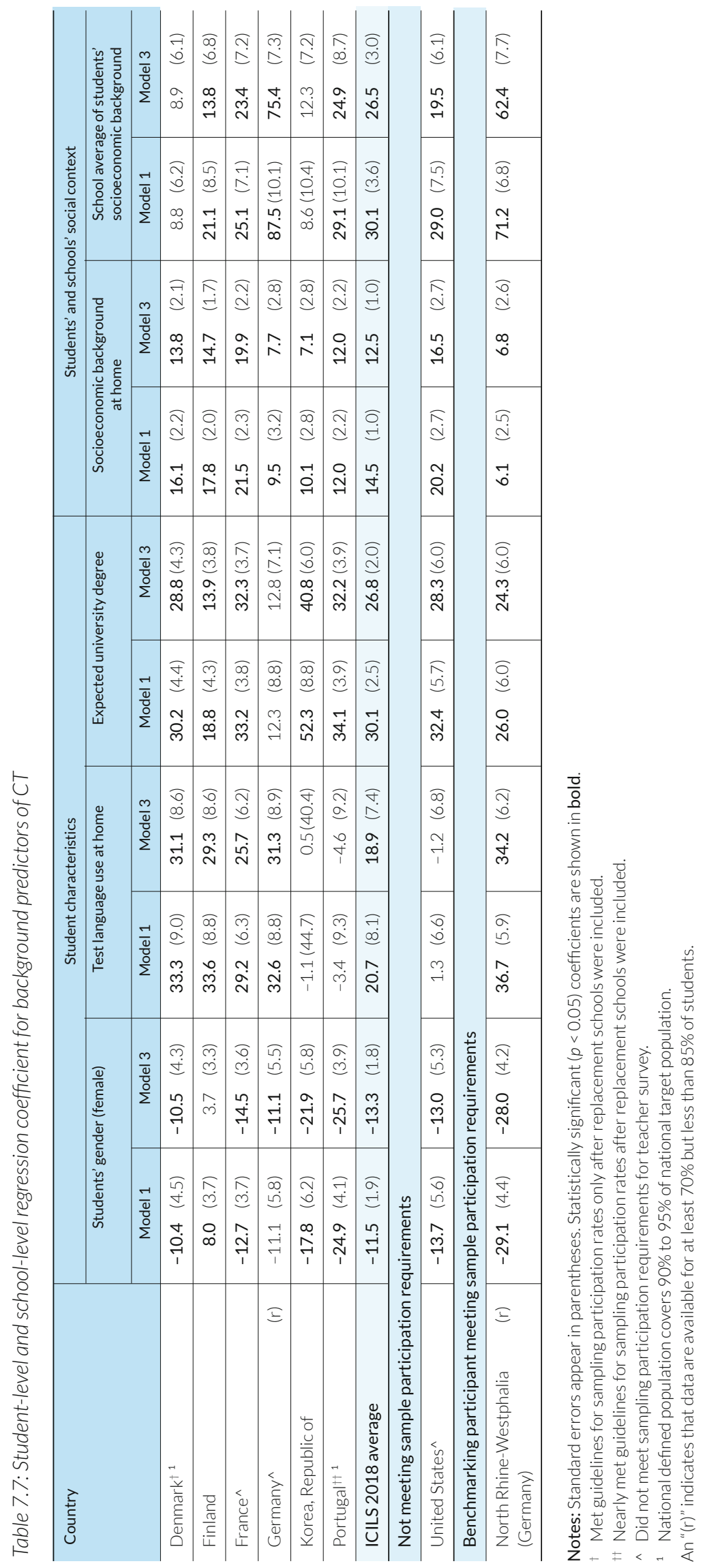




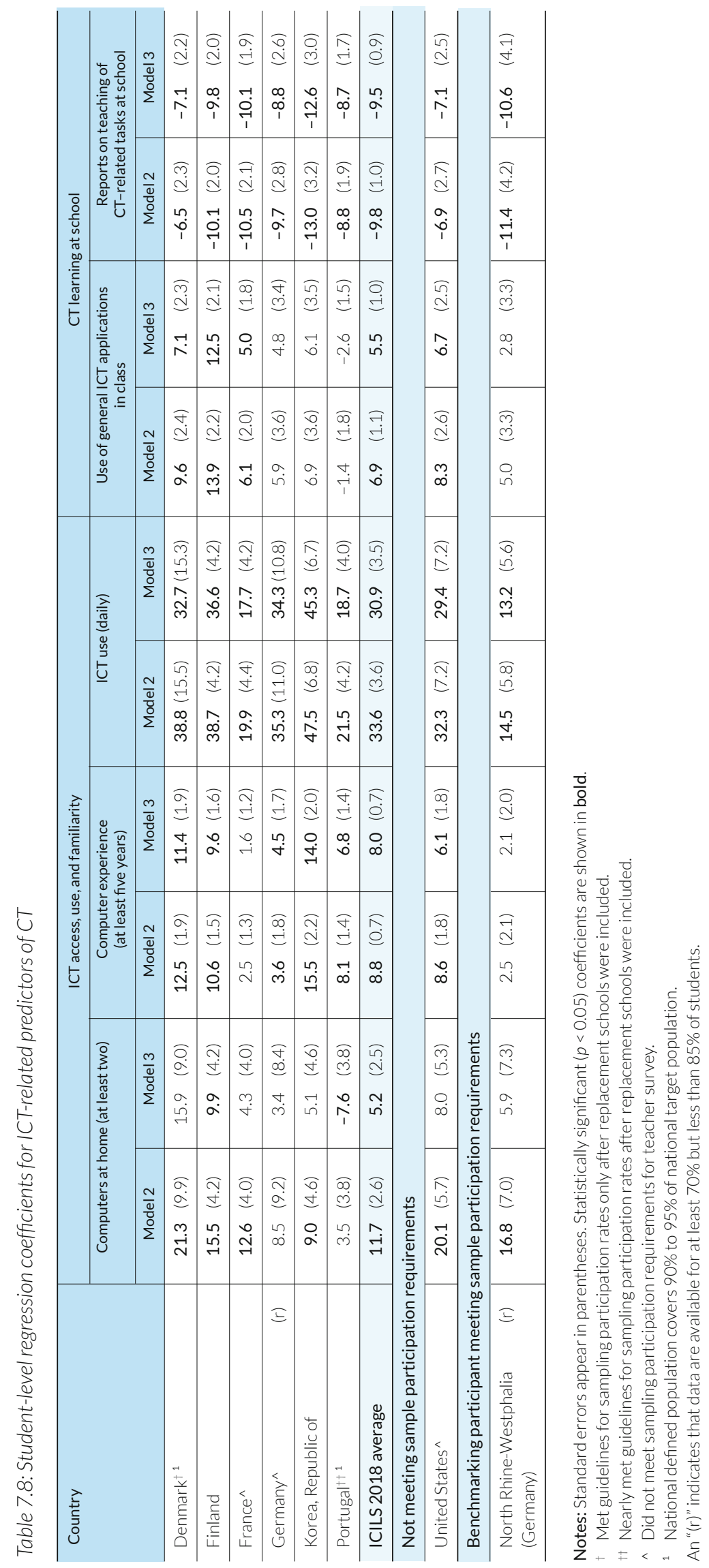


national standard deviation was associated with increases of about 10, 14, and six points respectively. Similar effects were recorded in these three countries for Model 3 where personal and social background factors were included.

Students' reports on learning of CT-related tasks during the current school year was a significant negative predictor in all countries for Models 2 and 3. One national standard deviation was on average associated with almost 10 score points in both models. It is possible that this finding is due to the fact that positive responses are related experiences with remedial instruction aimed at students who are less proficient with ICT. Alternatively, it is also possible that more knowledgeable students were better able to understand the content of the items and less inclined to give affirmative responses given the absence of more in-depth instruction related to these tasks at school.

For both models, schools' expectations of teachers' use of ICT for communication via ICT has significant positive effects on CT at the school level in Germany and Portugal. However, in both countries these effects decreased after controlling for social context variables in Model 3 (Table 7.9). The scale reflecting ICT resources at school was a significant positive predictor in Germany for Model 2 (24 score points) and Model 3 (11 score points), and also had significant positive associations with CT in Portugal after controlling for social context factors (Model 3: almost eight score points).

The average experience of teachers with using ICT for teaching did not show any significant associations with CT across countries except in the benchmarking participant North RhineWestphalia (Germany) (in both Models 2 and 3). Aggregated teacher reports on the use of ICT for student class activities was a significant positive Model 2 predictor in Finland and France, however, this association was no longer statistically significant in France in Model 3 after controlling for the schools' socioeconomic context.

When summarizing the significant effects across the six countries that participated in the CT option and met IEA sample participation requirements, we can see that (female) gender had significant negative net associations in four countries and a positive association in one country as part of Model 1. In the final Model 3 we found significant negative effects in five countries (Table 7.10). Furthermore, we observed that school-level factors related to ICT were not consistent predictors across countries. However, student-level factors related to ICT experience and learning tended to remain significant predictors when included in Model 3. Generally, the findings are roughly similar to those from the analyses of CIL. However, the observed negative effects of students' reports on learning of CT-related skills in class are noteworthy and warrant further investigation in future secondary analyses. 


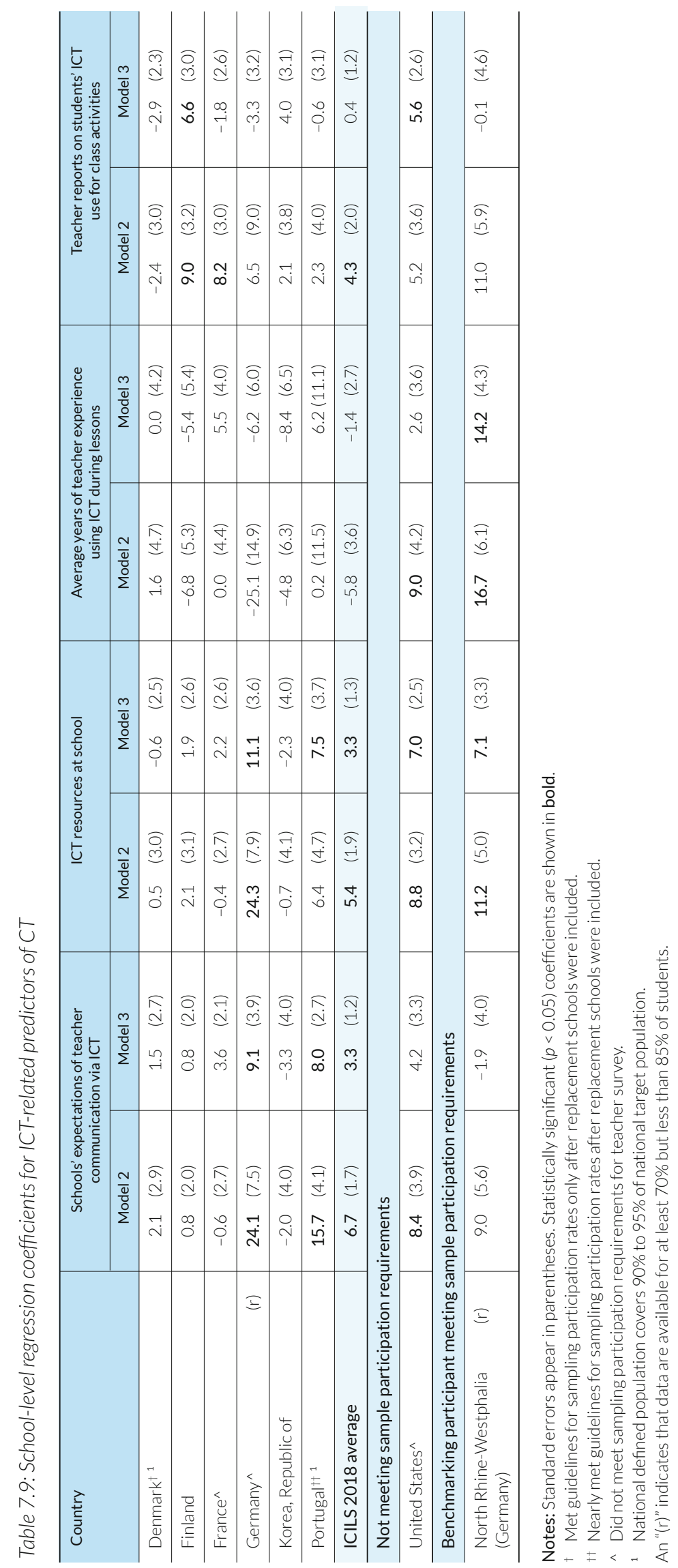




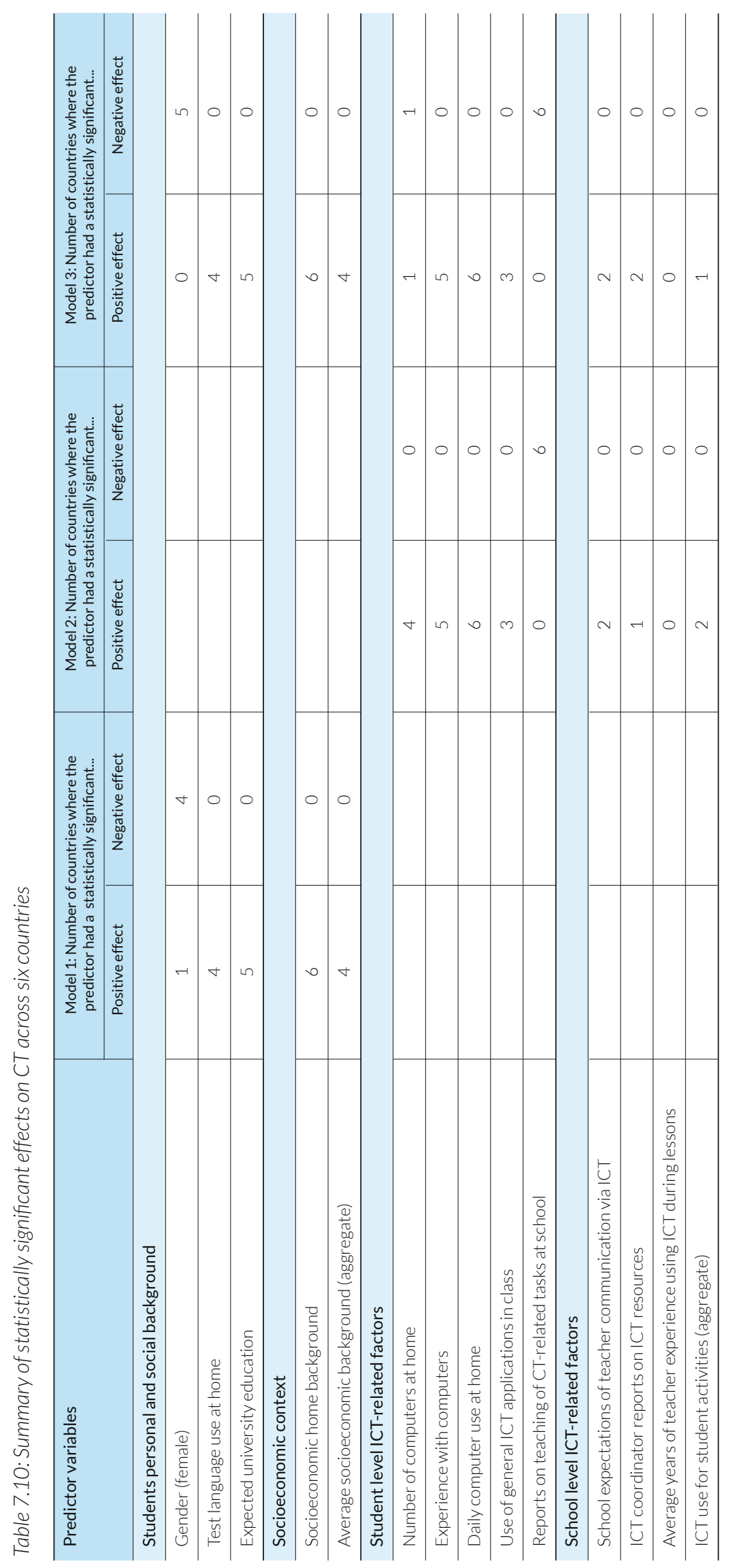




\section{References}

ACARA. (2012). National Assessment Program-ICT literacy. Years 6 \& 10 report. 2011. Sydney, Australia: Australian Curriculum, Assessment and Reporting Authority. Retrieved from https://www.nap.edu. au/_resources/NAP_ICTL_2011_Public_Report_Final.pdf.

ACARA. (2015). National Assessment Program -ICT literacy. Years 6 \& 10 report. 2014. Sydney, Australia: Australian Curriculum, Assessment and Reporting Authority. Retrieved from: http://www.nap.edu. au/_resources/D15_8761_NAP-ICT_2014_Public_Report_Final.pdf.

Cohen, J., \& Cohen, P. (1975). Applied multiple regression/correlation analysis for the behavioral sciences. Hillsdale, NJ: Lawrence Erlbaum Associates.

Fraillon, J., Ainley, J., Schulz, W., Duckworth, D., \& Friedman, T. (2019). IEA International Computer and Information Literacy Study 2018 assessment framework. Cham, Switzerland: Springer. Retrieved from https:// www.springer.com/gp/book/9783030193881.

Fraillon, J., Ainley, J., Schulz, W., Friedman, T., \& Gebhardt, E. (2014). Preparing for life in a digital age: The IEA International Computer and Information Literacy Study international report. Cham, Switzerland: Springer. Retrieved from https://www.springer.com/gp/book/9783319142210.

Fraillon, J., Schulz, W., Friedman, T., \& Meyer, S. (Eds.). (2020). IEA International Computer and Information Literacy Study 2018 technical report. Amsterdam, The Netherlands: International Association for the Evaluation of Educational Achievement (IEA). Manuscript in preparation.

Hatlevik, O.E. (2009). How to identify and understand digital literacy among 9th grade Norwegian students: Examining the influences from school and home on students' digital literacy. Nordic Journal of Digital Literacy, 4(3-4), 159-174.

Hatlevik, O.E., \& Christophersen, K.A. (2013). Digital competence at the beginning of upper secondary school: Identifying factors explaining digital inclusion. Computers \& Education, 63(1), 240-247. Retrieved from https://doi.org/10.1016/j.compedu.2012.11.015.

Hatlevik, O.E., Ottestad, G., \& Throndsen, I. (2014). Predictors of digital competence in 7th grade: a multilevel analysis. Journal of Computer Assisted Learning, 31, 220-231.

MCEECDYA [Ministerial Council for Education, Early Childhood Development and Youth Affairs]. (2010). National assessment program-ICT literacy. Years 6 \& 10 report. 2008. Carlton South, Australia: Curriculum Corporation. Retrieved from https://files.eric.ed.gov/fulltext/ED534805.pdf.

MCEETYA [Ministerial Council for Education, Early Childhood Development and Youth Affairs]. (2007). National assessment program-ICT literacy. Years 6 and 10 report. 2005. Carlton South, Australia: Curriculum Corporation. Retrieved from https://www.nap.edu.au/_resources/2005_ICTL_Public_Report_file_main.pdf.

Muthén, L.K., \& Muthén, B.O. (1998-2012). Mplus user's guide (seventh ed.). Los Angeles, CA: Muthén \& Muthén. Retrieved from https://www.statmodel.com/download/usersguide/Mplus\%20user\%20guide\%20 Ver_7_r3_web.pdf.

OECD. (2011). PISA 2009 results: Students on line. Digital technologies and performance (Volume VI). Paris, France: Author. Retrieved from http://dx.doi.org/10.1787/9789264112995-en.

Raudenbush, S. W., \& Bryk, A. S. (2002). Hierarchical linear models: Applications and data analysis methods. Newbury Park, CA: SAGE.

Román, M., \& Murrillo, J. (2013). Estimación del efecto escolar para la competencia digital. Aporte del liceo en el desarrollo de las habilidades TIC en estudiantes de secundaria en Chile [Investigation into the effect of school on digital competency. The contribution of the lyceum to the development of ICT in Chilean high school students]. In CEPPE, Desarrollo de habilidades digitales para el siglo XXI en Chile: ¿Qué dice el SIMCE TIC? [Developing digital skills for the twenty-first century in Chile: What does ICT SIMCE say?] (pp. 141-176). Santiago, Chile: LOM Ediciones.

Rutkowski, D., \& Delandshere, G. (2016). Causal inferences with large scale assessment data: Using a validity framework. Large-scale Assessments in Education, 4(6). Retrieved from https:// largescaleassessmentsineducation.springeropen.com/articles/10.1186/s40536-016-0019-1.

San Martín, E., Claro, M., Cabello, T., \& Preiss, D. (2013). Habilidades TICs para el aprendizaje y su relación con el conocimiento escolar en lenguaje y matemáticas [ICT skills for learning and their relationship to school knowledge in language and mathematics]. In CEPPE. Desarrollo de habilidades digitales para el siglo XXI en Chile: ¿Qué dice el SIMCE TIC? [Developing digital skills for the twenty-first century in Chile: What does ICT SIMCE say?] (pp. 229-248). Santiago, Chile: LOM Ediciones.

US Department of Education, National Center for Education Statistics. (2016). The nation's report card: 2014 Technology \& Engineering Literacy (TEL) report card at grade 8 (NCES2016119). Retrieved from https:// www.nationsreportcard.gov/tel_2014/. 
Open Access This chapter is licensed under the terms of the Creative Commons Attribution-NonCommercial 4.0 International License (http://creativecommons.org/licenses/by-nc/4.0/), which permits any noncommercial use, sharing, adaptation, distribution and reproduction in any medium or format, as long as you give appropriate credit to the original author(s) and the source, provide a link to the Creative Commons license and indicate if changes were made.

The images or other third party material in this chapter are included in the chapter's Creative Commons license, unless indicated otherwise in a credit line to the material. If material is not included in the chapter's Creative Commons license and your intended use is not permitted by statutory regulation or exceeds the permitted use, you will need to obtain permission directly from the copyright holder. 